\title{
A NECESSÁRia CONCEITUAÇÃo dE ESTADO PARA AS PESQUISAS NO CAMPO DAS POLÍTICAS DE EDUCAÇÃO AMBIENTAL: CONTRIBUIÇÕES DAS PERSPECTIVAS MARXISTAS
}

\author{
Leonardo Kaplan ${ }^{1}$ \\ Rodrigo Lamosa ${ }^{2}$
}

\begin{abstract}
Resumo
A proposta deste trabalho é realizar um aprofundamento teórico acerca do conceito de Estado, levando-se em consideração a agenda de pesquisas produzida no âmbito do Grupo de Discussão de Pesquisa (GDP) sobre Políticas Públicas em Educação Ambiental (EA). Na última edição desse GDP do Encontro Pesquisa em Educação Ambiental (EPEA), em 2017, foi reforçada a necessidade de se aprofundar o debate teórico acerca de conceitos centrais desse campo de pesquisas (Estado, sociedade civil, políticas públicas, sustentabilidade) para o desenvolvimento das investigações. A explicitação das bases epistemológicas desse conceito é central para a sustentação teórico-metodológica das pesquisas sobre políticas públicas. Em função da reiterada adoção de autores da perspectiva do materialismo histórico-dialético pelos pesquisadores do GDP sobre Políticas Públicas em EA, a ênfase, aqui, se dá no diálogo com autores marxistas (sobretudo Marx, Gramsci e Poulantzas), mas sem prejuízo de trabalhos com autores de outras filiações teórico-metodológicas e políticas, também indicados no presente artigo. Mediante a gama de autores inseridos nas diferentes tradições de pensamento indicadas (gregos antigos, teóricos políticos das origens da Modernidade, jusnaturalistas e contratualistas, liberais de variadas vertentes e marxistas), pretendemos estimular aprofundamentos teórico-conceituais nas pesquisas sobre políticas públicas em educação ambiental.
\end{abstract}

Palavras-chave: Políticas públicas. Educação ambiental.Estado.

\section{THE NECESSARY CONCEPTUALIZATION OF THE STATE FOR RESEARCH IN THE FIELD OF ENVIRONMENTAL EDUCATION POLICIES: CONTRIBUTIONS OF THE MARXIST PERSPECTIVES}

\begin{abstract}
The purpose of this paper is to provide a theoretical background on the concept of State, taking into account the research agenda produced by the Discussion Group of Researches (DGR) on Public Policies in Environmental Education (EE). The last edition of this DGR of the Research Meeting on Environmental Education (EPEA) in 2017 reinforced the need to deep/UFRRJen the theoretical debate about central concepts of this field of research (State, civil society, public policies, sustainability) for the development of investigations. The explication of the epistemological bases of this concept is central to the theoretical and methodological support of public policy researches. Due to the repeated adoption of authors from the perspective of historical-dialectical materialism by the researchers of DGR on Public Policies in EE, the emphasis here is on dialogue with marxist authors (especially Marx, Gramsci and Poulantzas), but without prejudice to authors' of other theoreticalmethodological and political affiliations, also indicated in this article. Through the range of

\footnotetext{
${ }^{1}$ Professor Doutor da Faculdade de Educação da Universidade do Estado do Rio de Janeiro (EDU/UERJ), Departamento de Estudos Aplicados ao Ensino (DEAE). leonardokaplan@ gmail.com.

${ }^{2}$ Professor Doutor da Universidade Federal Rural do Rio de Janeiro e do Programa de Pós-Graduação em Educação, Demandas Populares e Contextos Contemporâneos (PPGEduc/UFRRJ). rodrigo1281@ yahoo.com.br.
} 
authors inserted in the different traditions of thought indicated (ancient greeks, political theorists of the origins of Modernity, jusnaturalistsand contractualists, liberals of various strands and marxists), we intend to stimulate theoretical-conceptual deepening in the research on public policies in environmental education.

Keywords: Public policy. Environmental education.State.

\section{LA NECESARIA CONCEPCIÓN DE ESTADO PARA LAS INVESTIGACIONES EN EL CAMPO DE LAS POLÍTICAS DE EDUCACIÓN AMBIENTAL: CONTRIBUCIONES DE LAS PERSPECTIVAS MARXISTAS}

\section{Resumen}

La propuesta de este trabajo es realizar una profundización teórica acerca del concepto de Estado, tomando en consideración la agenda de investigaciones producida en el ámbito del Grupo de Discusión de Pesquisa (GDP) sobre las políticas públicas en educación ambiental (EA). En la última edición de ese GDP del Encuentro Investigación en Educación Ambiental (EPEA), en 2017, se reforzó la necesidad de profundizar el debate teórico acerca de conceptos centrales de ese campo de investigación (Estado, sociedad civil, políticas públicas, sostenibilidad) para el desarrollo de las investigaciones. La explicitación de las bases epistemológicas de este concepto es central para la sustentación teórico-metodológica de las investigaciones sobre políticas públicas. En función de la reiterada adopción de autores de la perspectiva del materialismo histórico-dialéctico por los investigadores del GDP sobre Políticas Públicas en EA, el énfasis, aquí, se da en el diálogo con autores marxistas (sobre todo Marx, Gramsci y Poulantzas), pero sin perjuicio de trabajos con autores de otras filiaciones teórico-metodológicas y políticas, también indicados en el presente artículo. A través de la gama de autores insertados en las diferentes tradiciones de pensamiento indicadas (griegos antiguos, teóricos políticos de los orígenes de la Modernidad, iusnaturalistas y contractuales, liberales de variadas vertientes y marxistas), pretendemos estimular el profundizamiento teórico-conceptual en las investigaciones sobre políticas públicas en educación ambiental.

Palabras clave: Políticas públicas. Educación ambiental. Estado.

\section{Introdução}

A proposta deste trabalho é realizar uma discussão teórica acerca das diversas concepções de Estado, entendendo ser este um exercício fundamental no tocante à discussão sobre as políticas públicas e, especialmente aqui, as políticas públicas de educação ambiental. Nas últimas décadas, muitas pesquisas têm sido realizadas, investigando as políticas públicas de educação ambiental (LAYRARGUES, 2003; CHÁVEZ; MATHEUS, 2004; SORRENTINO et al., 2005; SOTERO; SORRENTINO, 2010; CHADDAD, 2011; RODRIGUES; GUIMARÃES, 2010; KAPLAN, 2011;SILVA, 2014 apudNERY-SILVA; SANTANA, 2015). Trata-se de um campo fértil, que vem se consolidando e isso se evidencia nos periódicos do campo educacional e da educação ambiental (EA), bem como nos encontros desses campos, sendo que, no Encontro de Pesquisas em Educação Ambiental (EPEA), desde 2009, há um Grupo de Discussão de Pesquisas (GDP) sobre políticas públicas em EA.

Os textos que se voltam para a reflexão sobre as pesquisas em EA têm apontado, conforme Luiz Marcelo de Carvalho (2016), para a complexidade deste campo, ainda que, sem o devido respaldo teórico ou empírico, por vezes, se aponte para uma aparente construção de consensos. Segundo a proposição de Isabel Carvalho (2009 apud CARVALHO, 2016), a 
EA é entendida como uma esfera de confluência de dois campos já bastante complexos, o ambiental e o educacional, o que, certamente, traz significativas marcas em termos de sua heterogeneidade e das disputas e tensões na sua consolidação como um campo de pesquisa. Bastante influenciada por determinadas correntes do movimento ambientalista (BATISTA, 2007), ainda há uma forte necessidade de diálogo com autores, debates e lutas do campo educacional. Nesse sentido, a produção acadêmica em EA tem sido apontada como "ainda bastante aberta e com baixa definição", "com vários atravessamentos e um baixo perfil de definição" (CARVALHO, 2009, p. 128-129 apud CARVALHO, 2016, p. 148).

\section{Pesquisa em Educação Ambiental e Políticas Públicas}

A heterogeneidade do campo de pesquisa sobre políticas públicas é caracterizada pela variedade de abordagens, leituras, referenciais teórico-metodológicos, concepções, pressupostos e objetivos. Como expressão disto, na obra organizada por Ball e Mainardes (2011), autores de diferentes campos (da Sociologia das Políticas Educacionais, da Sociologia da Educação, Administração Escolar, estudos no campo do Currículo, Trabalho e Educação, Análise Crítica do Discurso, entre outros) e referenciais teóricos (pós-estruturalistas, descritivas e pluralistas, marxistas etc.) discutem variados aspectos teórico-metodológicos das análises das políticas educacionais. Inseridas no campo do Trabalho e Educação, e com referenciais teórico-metodológicos marxistas e da Análise Crítica do Discurso, estão as obras de Shiroma, Moraes e Evangelista (2007) e Evangelista (2014). Na primeira, é feito um histórico sintético e uma análise crítica do contexto social e histórico das principais políticas educacionais brasileiras, desde a década de 1930 até o final dos anos 1990. Já a segunda obra reúne textos de diferentes autores, contendo análises críticas sobre os mais recentes slogans veiculados nas políticas educacionais no Brasil, difundindo o ideário de organismos multilaterais, sobretudo o Banco Mundial: professor como o profissional que pode mudar um país, sociedade do conhecimento, inclusão e exclusão educacional, empreendedorismo, aprender a ser, educação ao longo da vida e educação eficiente como estratégia para o alívio da pobreza.

A mesma diversidade teórico-metodológica se aplica no caso das pesquisas sobre políticas públicas em EA. Santana e Lamosa (2016, p. 106) apontam para esta diversidade do campo e para os desafios políticos e epistemológicos que se renovam a cada edição do Encontro de Pesquisa em Educação Ambiental, com o fortalecimento do Grupo de Discussão de Pesquisas sobre Pesquisa em Educação Ambiental e Políticas Públicas. Em recentes EPEAs, realizados em 2011 e 2013, esse GDP produziu uma agenda com questões centrais para o debate, a serem consideradas pelos grupos de pesquisa e pesquisadores nesse campo. Santana (2014, p. 163-164) sistematizouas temáticas levantadas pelos pesquisadores presentes no referido GDP, no VI EPEA, em 2011:

1. Os conceitos de Estado e sociedade civil nas políticas públicas de educação ambiental.

2. Limites e estratégias para que as políticas públicas possam se constituir como políticas de Estado, políticas estruturantes, mais densas e menos instáveis.

3. As tensões indivíduo-instituição na formulação das políticas públicas.

4. O lugar das políticas públicas em educação ambiental no Estado (oquão estratégicas elas são, se são marginais... que condições têm para sair desse lugar mais marginalizado?).

5. A relação das políticas públicas de educação ambiental com outras políticas públicas, destacadamente, as de educação (reiteradas várias vezes), mas também as demais políticas sociais, de saneamento, de saúde etc.

6. Estudo das condições objetivas das políticas públicas de educação ambiental (como se constroem as equipes, orçamentos, quais são as condições de se desenvolver políticas) 
7. Mais estudos de caso (pontuais e mais abrangentes - municipais, estaduais e federais) da materialização das políticas públicas de educação ambiental com vistas a traçar diagnósticos e mapeamentos.

8. Os diferentes interesses da sociedade civil em jogo na definição das políticas de educação ambiental (relação das políticas de EA com as demandas dos movimentos sociais, sobretudo, ligados à educação).

No GDP do VII EPEA, em 2013, foram adicionados outros três temas:

9. Pesquisas enfocando os aspectos ambientais e educacionais, em especial aquelas que avaliam os resultados e/ou consequências das políticas públicas quanto a tais aspectos.

10. Análise dos resultados das políticas públicas (considerando a carência na divulgação dos resultados das políticas públicas pelo próprio Estado).

11. Buscar explicitar elementos resultantes da investigação que indiquem perspectivas de uma efetiva emancipação humana, evitando, com isto, a desilusão e o desânimo (tanto para o pesquisador quanto para os sujeitos das pesquisas desenvolvidas). (ibidem).

Por fim, no VIII EPEA, em 2015, Santana e Lamosa (2016, p. 111) lembram que foram propostos onze novos eixos temáticos:

12) Pesquisas que caracterizem a Gestão Ambiental Pública no Estado brasileiro;

13) Pesquisas que investiguem os instrumentos de participação que caracterizam a Gestão Ambiental Pública.

14) Mais estudos sobre a atuação dos sujeitos prioritários da Gestão Ambiental Pública.

15) Investigações sobre a formulação das propostas de Gestão Ambiental Pública (quem são os sujeitos que vem realizando a formulação das políticas públicas para a Gestão Ambiental Pública? Como esses sujeitos vêm atuando?).

16) Trabalhos que estudem a relação entre as políticas internacionais e as políticas nacionais e locais acerca das definições sobre a Gestão Ambiental Pública.

17) Pesquisas que abordem as questões epistemológicas referentes às políticas públicas de EA.

18) Trabalhos que enfoquem as diversas formas de privatização das políticas públicas de EA.

19) Investigações centradas nas conquistas em relação à construção da Gestão Pública Ambiental no Brasil.

20) Pesquisas que investiguem os processos de formulação e implementação das políticas e programas municipais e estaduais de EA.

21) Investigações sobre os limites e possibilidades de fortalecimento da democracia nos processos de formulação da Gestão Ambiental Pública.

22) Trabalhos que investiguem o regime de colaboração entre instituições públicas para a organização da Gestão Pública Ambiental.

Pela amplitude de temáticas, vemos que se trata de um campo bastante promissor. Percebe-se uma oscilação em termos do número de trabalhos apresentados nesse GDP ao longo dos EPEAs, ficando entre onze e vinte e uma apresentações, a partir de sua constituição, em 2009. Entretanto, a riqueza da variedade de temas, objetivos e metodologias que formam o conjunto desses trabalhos vem sendo reconhecida durante os encontros (SANTANA; LAMOSA, 2016, p. 108).

Em termos de temáticas, há desde investigações mais pautadas em estudos de caso a estudos mais amplos sobre políticas, leis e/ou programas federais, estaduais ou municipais de educação ambiental (SANTANA; LAMOSA, 2016, p.109). Em relação aos aspectos metodológicos, os instrumentos de coleta de dados e de procedimentos de análise também têm sido bastante diversificados: dentre os primeiros, no VIII EPEA, foram destacadas a pesquisa histórica, a pesquisa documental, a observação, a entrevista semiestruturada e a aplicação de questionário; como procedimentos de análise, identificou-se a análise de conteúdo e a análise do discurso (SANTANA; LAMOSA, 2016, p. 110-111). 
Quanto aos referenciais teórico-metodológicos, no VIII EPEA, os coordenadores do GDP constataram a presença marcante do materialismo histórico-dialético, notado desde as edições anteriores do GDP (SANTANA; LAMOSA, 2014; FERRARO, 2012 apudSANTANA; LAMOSA, 2016, p.110). Certamente, são muitas as demandas de aprofundamento das pesquisas sobre políticas públicas em EA.

Neste trabalho, pretendemos contribuir com a primeira temática levantada para compor a agenda de pesquisas nesse campo, especialmente tratando aqui dos conceitos de Estado produzidos por autores de diversas tradições teórico-metodológico-políticas. Um segundo movimento que pensamos ser indispensável, mas não será possível apresentar neste texto, é a identificação, nas dissertações e teses do campo da EA, de quais autores, concepções e interpretações acerca destes vem sendo empregadas nas pesquisas sobre políticas públicas em educação ambiental. No VIII EPEA, no levantamento feito pelos coordenadores do GDP sobre Pesquisa em Educação Ambiental e Políticas Públicas, constatou-se que:

Entre os autores do campo da educação ambiental os mais citados também se situam no âmbito do materialismo histórico-dialético, como Loureiro (2003, 2012), Loureiro et. al. (2005), Quintas (2006, 2009), Tozoni-Reis (2011), Lamosa (2010), Anello (2009). Outros autores, também considerados de perspectiva crítica, foram referenciados, tais como Guimarães (2004, 2009), Layrargues (2002, 2012), Layrargues e Lima (2011), Sorrentino (2005) e Carvalho (2001, 2004) (SANTANA; LAMOSA, 2016, p. 110).

Consideramos que este tipo de estudo sobre as formulações que têm sido adotadas nas pesquisas do campo ajuda a dar densidade teórica a essas discussões, indicando de qual Estado os pesquisadores do campo falam, quais suas possibilidades e limites, bem como os papéis das políticas educacionais (no contexto das políticas sociais) e, particularmente, das políticas de educação ambiental. Em alguns momentos, devido a essas diferentes concepções teórico-metodológicas, epistemológicas e políticas no que diz respeito aos sentidos das pesquisas sobre políticas públicas de educação ambiental, e sobre a natureza das próprias políticas públicas, têm sido produzidos diversos tensionamentos no campo de pesquisa em EA. Assim, nos parece fundamental o aprofundamento do debate acerca desses diferentes referenciais teórico-metodológicos e suas implicações para as pesquisas. É nessa direção que caminha este trabalho.

Em 2017, na IX edição do EPEA, realizada na Universidade Federal de Juiz de Fora (UFJF), o GDP sobre Pesquisa em Educação Ambiental e Políticas Públicas recebeu, ao todo, vinte e cinco trabalhos, tendo sido a edição com a maior quantidade de trabalhos registrada desde a formação do grupo. Nos dois dias de encontro desse GDP, a dinâmica proposta pela coordenação e aprovada pelos presentes consistiu em, inicialmente, resgatar, brevemente, o histórico recente do mesmo em termos do significativo número de trabalhos apresentados em cada edição e das discussões que vêm sendo travadas nesse espaço.

Posteriormente, foi apresentada a agenda de pesquisas construída pelos participantes desse GDP desde 2011. Sucedeu-se uma rodada em que todos os presentes puderam se apresentar. Como já fora observado em outras edições, havia desde participantes mais experientes (tanto no campo de pesquisas da EA, nos EPEAs e/ou neste GDP) até pesquisadores recém-chegados. Em seguida, foi apresentada uma sistematização inicial dos trabalhos aprovados para essa edição do GDP, indicando suas temáticas, objetivos, referenciais teórico-metodológicos e instrumentos de coleta de dados e procedimentos analíticos.

Para o segundo dia de reuniões, a proposta da coordenação foi que os presentes se dividissem em pequenos grupos para discutir suas concepções acerca de quatro conceitoschave sugeridos: Estado, sociedade civil, políticas públicas e sustentabilidade. Para cada 
conceito, a orientação era de que os grupos indicassem com quais autores vinham dialogando em seus trabalhos (em termos de seus referenciais teórico-metodológicos ou para realizar a crítica dos mesmos) e noções ou expressões-chave que caracterizam cada autor.

Os trabalhos reunidos no GDP foram organizados, diferente do que havia ocorrido na edição anterior, a partir de seis eixos temáticos: 1) Unidades de Conservação, 2) Políticas de EA (Internacional, Federal, Estadual e Municipal), 3) EA no contexto escolar, 4) EA e o controle social das políticas públicas e EA, 5) Justiça Ambiental e 6) Estado da arte do campo. Em relação à edição anterior, não houve trabalhos para eixos como EA e Turismo e EA e licenciamento ambiental.

A diversidade de temas explorados pelos trabalhos do GDP também se manteve:Unidades de Conservação - trabalho 0048, Políticas de EA (Internacional, Federal, Estadual e Municipal) - trabalhos 0011; 0025; 0028; 0077; 0124; 0182; 0193; 0201; 0263,EA no contexto escolar - trabalhos 0091; 0138; 0216; 0218; 0222; 0228; 0249, EA e o controle social das políticas públicas -trabalho 0255, EA e Justiça Ambiental - trabalhos 0129; 0140; 0163; 0167; 0178; 028,Estado da Arte do campo - trabalho 0143. Embora divididos em eixo temáticos, os trabalhos apresentados no GDP buscaram relacionar seu objeto empírico com a historicidade da emergência da EA nas políticas públicas.

Com relação aos conceitos de Estado e sociedade civil, objeto do presente artigo, verificamos uma diversidade de autores e perspectivas teórico-metodológicas mencionados pelos participantes do GDP em suas pesquisas, ainda que os mesmos não necessariamente estivessem sendo adotados e referenciados nos trabalhos apresentados naquela edição do EPEA. Em termos do conceito de Estado, os participantes indicaram os seguintes autores clássicos e contemporâneos: Karl Marx, Friedrich Engels, Vladmir Vladimir Ilyich Ulyanov (Lenin), Antonio Gramsci, NicosPoulantzas, David Harvey, John Locke, Carlos Roberto Jamil Cury, Francisco Weffort, Eloisa Höfling e Leonardo Secchi. Quanto ao conceito de sociedade civil, foram mencionados Karl Marx, Antonio Gramsci, Virginia Fontes, Sonia Regina de Mendonça, Maria da Glória Gohn, Jean-Jacques Rousseau, Jürgen Habermas, Norberto Bobbio e Anthony Giddens.

$\mathrm{Na}$ edição mais recente do EPEA, em 2017, foi definido pelos participantes do GDP sobre Pesquisa em Educação Ambiental e Políticas Públicas manter a agenda de pesquisa elaborada nas edições anteriores, tendo o grupo se dedicado a realizar debate acerca de conceitos considerados fundamentais para o amadurecimento do campo de pesquisas. A decisão foi fruto do debate proposto pela coordenação do GDP sobre a necessidade de estabelecer uma maior ressonância dessa agenda para as pesquisas sobre políticas públicas em educação ambiental.

A proposta de recuperamos parte do que consideramos fundamental nesse debate não tem qualquer pretensão de esgotar as questões ou de reproduzir, em espaço tão restrito, a riqueza das discussões produzidas por esse coletivo. Como foi verificado, na fala dos participantes do GDP, a adoção de um significativo conjunto de autores identificados com o referencial teórico-metodológico do materialismo histórico-dialético como referências importantes para as concepções de Estado presentes nas pesquisas, nosso recorte, aqui, se concentra em abordar seus conceitos de Estado.

\section{Estado e Poder: aspectos teóricos e metodológicos}

Um conceito absolutamente central e polissêmico nas Ciências Sociais e no campo educacional é o de Estado. Compreender o fenômeno educativo, particularmente o escolar, as políticas públicas, os diferentes modos de organização social e as diversas formas de sociabilidade passa por pensar suas mediações com o Estado. A formação e as reflexões sobre 
o Estado são processos que, ainda que não tenham se iniciado na era moderna ${ }^{3}$, têm assumido uma nova configuração a partir do início do século XV. Desde então, têm sido feitas diversas análises e tentativas de compreender a natureza desse Estado Moderno por distintas tradições teóricas, incluindo o liberalismo e o marxismo. Assinalamos, aqui, a importância de compreendermos o Estado em sua dimensão histórica, como produto das relações sociais e da correlação de forças em uma determinada sociedade. Para tal, cabe resgatar as diferentes concepções sócio-historicamente formuladas para a análise da natureza do Estado.

O conceito Estado, ao longo da história,foi hegemonizado na historiografia ${ }^{4}$ brasileira por um conjunto de formulações teórico-metodológicas. Essa hegemonia difundiu no senso comum um sentido que confunde o Estado, ora com um determinado governante, ora com alguma agência da administração pública. Tais formulações são responsáveis por retirar das relações que formam o Estado suas mediações com a sociedade, produzindo uma espécie de coisificação do Estado (MENDONÇA, 1998).

$\mathrm{Na}$ Modernidade, diferentes autores têm feito análises e tentativas de compreender a natureza do Estado. Faz-se necessário, portanto, que não se parta de uma leitura não historicizada e unívoca (ou, ainda, evolucionista), compreendendo que houve, e ainda há, pontos de vista diferentes e divergentes, por conta do período histórico e do local onde foram produzidas tais análises e, também, da posição social e consequente comprometimento ideológico (com a manutenção ou com a transformação da ordem vigente), do produtor de tal leitura.

Assim, reiteramos a importância de pensarmos o Estado em sua dimensão histórica, como produto das relações sociais e da correlação de forças em uma determinada sociedade. Gruppi (1980) reúne uma boa síntese das concepções de Estado de diversos autores clássicos. Outra excelente obra que sistematiza as principais correntes teóricas que se debruçaram a formular sobre a natureza do Estado, na teoria política clássica, é de Montaño e Duriguetto (2011). Nela, seguem-se sínteses sobre os pensadores da Grécia Antiga,o jusnaturalismo e contratualismo de Hobbes e Rousseau, a tradição liberal (de Tocqueville, Keynes e Hayek),chegando à concepção de Estado e sociedade civil em Hegel, passando pelo Estado racional moderno de Webber. A ênfase é nos autores de tradição marxista, como Marx e Engels, Lenin e Gramsci.

Em outra leitura indispensável para quem pretende mergulhar nas teorias de Estado, Carnoy (2015, p. 11) ressalta a importância de sua obra em termos de:

1) atrair a atenção para o Estado como objeto de investigação; 2) demonstrar que há discussões sobre o que é o Estado, o que ele faz e como funciona; 3) mostrar que as divergências inerentes a essas discussões refletem diferentes pontos de vista sobre a sociedade e o papel do Estado na sociedade; 4) mostrar como diferentes pontos de vista sobre o Estado implicam políticas diferentes de mudança social, tanto em relação aos meios quanto aos seus fins (grifo do autor).

Esse livro reúne as chamadas teorias do Estado do Bem-Comum, a doutrina clássica (sobretudo de Hobbes, Locke e Rousseau), a doutrina liberal clássica (conforme Adam Smith, Jeremy Bentham, James Mill e John Stuart Mill), a visão pluralista (Joseph Schumpeter, de forma destacada), o corporativismo (Philippe Schimitter e outros), as compreensões e teorias marxistas do Estado (Marx, Engels, Lenin, Gramsci, Althusser, Poulantzas, Milliband). Trata,

\footnotetext{
${ }^{3}$ Considerando-se, por exemplo, a Grécia Antiga e as preocupações e estudos sobre o Estado e os governos, e suas relações entre si e com o povo. Montaño e Duriguetto (2011, p. 19) nos lembram que a vida na pólis grega, assim como na res publica romana, despertaram o interesse e a reflexão de filósofos e autoridades políticas. Assim como a pulverização das cidades-Estado na Itália também determinou a preocupação com a unificação delas.

${ }^{4}$ Nos referimos aqui a produção nas variadas áreas de pesquisa, sem se restringir à História como ciência.
} 
também, de muitas outras vertentes.É possível perceber, portanto, toda a complexidade envolvida nesse debate sobre as concepções de Estado.

Segundo Gruppi (1980, p. 10-11), Nicolau Maquiavel (1469-1527), ao refletir sobre a realidade de sua época, elaborou não uma teoria sobre o Estado Moderno, mas, sim, uma teoria de como se formam os Estados. Em O príncipe, trata da questão da unificação da Itália, com a união dos antigos principados. No contexto da derrota da República e restauração da Monarquia dos Médici, que levou Maquiavel ao exílio, sua preocupação central foi dar instruções ao Príncipe, visando a unificação da Itália (MONTAÑO; DURIGUETTO, 2011).

Partindo de um pensamento pautado na realidade, científico e experimental, vendo as coisas como elas são e estão ("verdade efetiva", nos seus termos) e não como elas deveriam ser, diferencia a política da moral, já que a primeira é a arte do possível, da realidade que pode ser efetivada, enquanto a segunda trata do que deveria ser (GRUPPI, 1980, p. 10). Nesse sentido, Maquiavel visou desvendar uma ética política (não moral), independente da vida privada e da religião, em que a ação política e o ator político fossem julgados pelos resultados, e não pelos meios empregados.

Desse modo, segundo Montaño e Duriguetto (2011, p. 21), o autor muda os rumos das análises políticas anteriores. Enquanto os gregos estudavam o político (no campo institucional), Maquiavel se dedica à análise de a política (referente ao espaço de ação), outorgando certa historicidade à ação política. Nos Discursos sobre a primeira década de Tito Lívio, ele havia dito que o poder baseia-se na democracia, no consentimento do povo (no caso, a burguesia de sua época). Posteriormente, em $O$ príncipe, pensando na construção de um Estado unitário e moderno (Estado Absoluto) coloca que o poder do Estado funda-se no terror (ou na força, atualizando esse conceito). Assim sendo, é melhor para um príncipe ser temido a ser amado, já que, como é difícil juntar as duas coisas, aquele que esperar gratidão por ter sido bondoso com os seus súditos será derrotado.

Maquiavel avança ao incorporar ao debate político uma distinção então não considerada entre Estado e sociedade. O Estado, antes chamado de pólis pelos gregos e de res pública pelos romanos, é o espaço onde o ator político por excelência (o príncipe) atua. Ali ele exerce sua coerção e procura o consenso; ali se gera e desenvolve o poder político; ali se criam as leis que regulam a ordem social. Por sua vez, a sociedade é o que Maquiavel entende por privado; o espaço onde o povo desenvolve as atividades econômicas, onde se gera a propriedade privada, onde se constrói a família. E é aqui que o príncipe (o Estado) não deve interferir (MONTAÑO; DURIGUETTO, 2011).

O pensamento jusnaturalista, cujos maiores expoentes foram Thomas Hobbes (15881679), John Locke (1632-1704) e Jean-Jacques Rousseau (1712-1778), se contrapôs historicamente às teorias do Direito Divino, através de formulações como as realizadas por Jean Bodin (GRUPPI, 1980).

A visão contratualista rompe com as oriundas do pensamento religioso vigente no período do Absolutismo, as quais buscavam explicar e legitimar a origem do poder político concentrado e assimétrico. No entendimento dos contratualistas, se os homens e mulheres vivessem livremente em sociedade, haveria uma luta de todos contra todos pela sobrevivência, sendo, portanto, necessária uma mediação por mecanismos de contenção, firmando um contrato social a ser garantido pelo Estado instituído. Para legitimar esse argumento são mencionados atributos naturais, destacando um instinto selvagem intrínseco e comum a toda humanidade. Como este era um problema inerente aos homens e às mulheres, deveria ser resolvido sem intervenções externas, antes asseguradas pelos princípios divinos. Ao Soberano caberia o exercício da violência de modo a assegurar a pacificação proveniente da demarcação de um único poder a ser exercido sobre todos (FONTES, 2006).

A desigualdade de poder seria necessária visto que, em condições de poderes iguais, a humanidade atingiria uma situação de isolamento, selvageria e barbárie, de guerra de todos 
contra todos. Essa situação contida, legal, com regras conhecidas, seria a forma de evitar esse confronto. A regulação desse poder desigual caberia, portanto, a uma pessoa, o Soberano. O contrato social - ou, em outras palavras, o Estado - seria, em última instância, um mal necessário. A esse Estado caberia assegurar direitos cuja origem derivaria da natureza, no caso, o direito à vida, à liberdade e à propriedade. Nesse pacto se origina, também, o termo sociedade civil, enquanto entidade antitética ao estado de natureza. Os termos sociedade civil,Governo e Estado seriam quase equivalentes (BOBBIO, 1992 apud FONTES, 2006).

A lógica da racionalidade estaria presente nesse acordo entre os homens, contrapondo os elementos irracionais instintivos, atribuídos à natureza humana. Nesse sentido, as leis e demais regras estabelecidas se encontrariam respaldadas pela racionalidade, convertendo um Estado de pura violência em expressão da razão: a pior expressão da natureza teria produzido sua melhor forma (FONTES, 2006). Tem-se, aí, o estabelecimento de uma contradição, já que o Estado freia a natureza humana, mas resulta de um contrato que tensiona a liberdade e a propriedade.

Desde sua origem até meados do século XIX a matriz liberal jusnaturalista demarcou importante campo no debate acerca do Estado. Entre os mais importantes teóricos jusnaturalistas, Rousseau teve o mérito de estabelecer como fundamento do Estado um princípio que, não somente em sua forma, mas também em seu conteúdo, é expressão da vontade geral, rompendo com os desígnios naturais ou espirituais. Mas, ao conceber a vontade apenas em sua forma individual e a vontade geral, não como o racional em si e para si da vontade, mas como vontade comum que ressalta as vontades individuais, a associação dos indivíduos foi entendida como um contrato, cujo fundamento é, então, o arbítrio, a opinião, a adesão expressa e facultativa.

De acordo com Hegel, importante crítico das formulações jusnaturalistas, a compreensão rousseauniana tinha avançado no entendimento de que o contrato social não se refere, apenas, às diferentes ordens políticas que dele resultam, tanto a despótica quanto a democrática, mas corresponde como pressuposto uma formação econômico-social. Segundo Coutinho (2011), o contrato social, na análise de Rousseau, não tem como meta a constituição de uma esfera pública especializada e separada, como em Hobbes e Locke, clássicos teóricos jusnaturalistas, mas é algo que "reorganiza a própria forma de articulação entre o público e o privado, de modo que a sociabilidade se torne um elemento constitutivo imanente ao próprio indivíduo: a vontade geral e o interesse comum" (COUTINHO, 2011, p. 18). O interesse comum não é algo externo que se imponha ao indivíduo, mas "uma emanação possível de sua própria individualidade" (COUTINHO, 2011, p.19).

No século XIX, inicialmente, através de Hegel e, principalmente, a partir de Marx, foi realizada uma dura crítica à matriz liberal jusnaturalista. A crítica hegeliana pautou-se, justamente, no caráter conciliatório das interpretações acerca do processo de formação do Estado, tal como descrito pelos jusnaturalistas. A crítica hegeliana se concentrou sobre o contrato social elaborado nas formulações jusnaturalistas que retiraria da sociedade seu papel histórico, tornando-a coadjuvante na história.

Hegel pode ser considerado o primeiro entre os autores clássicos a superar essa formulação contratualista (BRANDÃO, 2006). Os indivíduos não escolhem se participam ou não do Estado, como presume a tese do contrato social, mas são formados por ele: "somente como membro do Estado é que o indivíduo ascende à sua objetividade, verdade e moralidade" (BRANDÃO, 2006, p. 107).

Um dos problemas fundamentais da formulação jusnaturalista, segundo Hegel, é terem procurado identificar o Estado com ele deveria ser, ao contrário de tentar entendê-lo como é. Estes teriam produzido uma teoria do contrato em que pressupõem a existência de indivíduos livres para fazerem escolhas. Segundo Brandão (2006, p.111), a partir das críticas de Hegel, 
"completa-se o movimento iniciado por Maquiavel, voltado para apreender o Estado tal como ele é, uma realidade histórica, produzida pela ação dos homens ".

$\mathrm{Na}$ formulação hegeliana, o Estado é a superação do reino do particularismo, expresso na sociedade civil, onde a luta de todos contra todos é orientada pelos interesses particulares. A formulação hegeliana, a despeito de sua enorme influência, é superada, em relação à teoria do Estado, na obra de Marx, que entende que o mesmo só pode representar a universalidade, como proposto por Hegel, na aparência. O Estado, apesar de Marx nunca ter elaborado uma teoria sistematizada do Estado, é apreendido em sua obra a partir do seu papel histórico no desenvolvimento do capitalismo.

Ao longo de toda a obra produzida por Marx (1968), fundamentalmente influenciada pela herança hegeliana, tanto em sua apropriação, quanto na refutação das apropriações realizadas pelos intelectuais hegelianos, não existe um estado de natureza. A sociabilidade humana se forma ao longo da história, dependendo do lugar que ocupam no processo de produção. Os homens podem ser proprietários, ou seja, possuidores dos meios de produção, ou serem obrigados a vender sua força de trabalho para sobreviverem. Pertencem, portanto, a uma das duas classes fundamentais: burguesia ou proletariado. Assim, a matriz teórica formulada por Marx é, ao mesmo tempo, histórica e classista.

A origem do Estado, na formulação de Marx (2003), reside na apropriação privada da riqueza social, ou seja, com a introdução da propriedade privada na história ou, como denominado no Manifesto do Partido Comunista (1998), na pré-história dos homens, quando estes ainda estão submetidos à divisão entre as classes sociais. A partir desse momento, certa classe passou a dominar os meios de produção, subordinando os demais que não tiveram outra opção a não ser vender suas forças de trabalho. O Estado surge, para essa tese, visando assegurar a divisão estabelecida entre as classes sociais, conseguindo manter os trabalhadores sob a ordem instituída, sem se rebelarem contra a propriedade dos meios de produção (ENGELS, 2006). O Estado, na formulação de Marx (1996), não teria nada de natural, sendo concebido historicamente, através da luta entre as classes sociais.

A tese sobre o Estado, produzida por Marx de forma não sistematizada, mas que claramente está presente ao longo de sua obra, substitui o binômio Estado (sociedade) de natureza-Estado (sociedade) civil pelo binômio sociedade civil-sociedade política. Esta substituição foi fundamental, pois o mesmo tempo em que nega a existência de um estado natural da humanidade, identifica que a sociabilidade dos homens não se esgota na política (NETTO, 2012).

Ao contrário do que se imagina e do que costuma ser abordado, Marx não desenvolveu uma única teoria da política e/ou do Estado. No limite, as contribuições de Marx vão no sentido da crítica do Estado burguês, apontando para sua tomada e destruição. As concepções marxianas do Estado devem ser deduzidas das críticas de Marx a Hegel, do desenvolvimento da teoria de Marx sobre a sociedade capitalista (em especial, sua crítica da economia política clássica) e de suas análises de conjunturas históricas específicas (a revolução de 1848, na França, e a ditadura de Luis Bonaparte, ou a Comuna de Paris, em 1871) (CARNOY, 2015, p. 67). Assim, ainda que possamos encontrar uma unidade no desenvolvimento da concepção de Marx acerca do Estado, cabe, também, reconhecer diferentes momentos dessa elaboração teórica.

A questão do Estado aparece na obra marxiana em sua Crítica da filosofia do direito de Hegel (MARX, 2013), escrito em 1843. No entanto, segundo Carnoy (2015, p. 67), a primeira vez em que Marx expressou sua formulação completa de que a burguesia (como classe dominante) estende seu poder ao Estado foi n'A ideologia alemã (MARX; ENGELS, 2017), de 1845-1846. Essa concepção se desenvolve no Manifesto do Partido Comunista (MARX; ENGELS, 2017a), escrito em 1848. Por sua vez, as análises que Marx faz da luta de classes na França, entre 1848 e 1852, atravessada pelos golpes de Estado desferidos por Luis 
Bonaparte, foram publicadas nas obras A luta de classes na França (MARX, 2008a), O dezoito Brumário de Luis Bonaparte (MARX,2011) e A guerra civil na França (MARX, 2008b), que faz um balanço sobre a experiência da Comuna de Paris, em 1871.

Finalmente, há também importantes elementos sobre a concepção marxiana de Estado na Crítica do programa de Gotha (MARX, 2012), publicado em 1875. Isso ajuda a entender o porquê da grande variedade de interpretações, baseadas nessas diferentes fontes, levando a um considerável debate entre os marxistas, indo desde uma posição que defende a visão leninista àquelas que veem uma teoria do Estado claramente refletida na análise política e econômica de Marx, ou tomam o Estado autônomo do Dezoito Brumário (de Luís Bonaparte) como a base para a análise da situação atual (CARNOY, p. 67).

Assim, inicialmente, Karl Marx fez uma revisão crítica da filosofia do direito de Hegel (MARX, 2013). Marx define a sociedade civil, enquanto sociedade burguesa, como a esfera da produção e da reprodução da vida material, a estrutura econômica (MONTAÑO; DURIGUETTO, 2011), entendendo que

[...] as relações jurídicas, bem como as formas do Estado, não podem ser explicadas por si mesmas, nem pela chamada evolução geral do espírito humano; essas relações têm, ao contrário, suas raízes nas condições materiais de existência, em suas totalidades, condições estas que Hegel (...) compreendia sob o nome de "sociedade civil" (MARX, 2008, p. 47).

Sucintamente, o resultado de sua análise:

[...] na produção social da própria existência, os homens entram em relações determinadas, necessárias, independentes de sua vontade; essas relações de produção correspondem a um grau determinado de desenvolvimento de suas forças produtivas materiais. A totalidade dessas relações de produção constitui a estrutura econômica da sociedade, a base real sobre a qual se eleva uma superestrutura jurídica e política e à qual correspondem formas sociais determinadas de consciência. O modo de produção da vida material condiciona o processo de vida social, política e intelectual. Não é a consciência dos homens que determina o seu ser; ao contrário, é o seu ser social que determina sua consciência (MARX, 2008, p. 47).

Assim, na concepção marxista, ao contrário da hegeliana, a sociedade civil é que determina a natureza do Estado, sendo este Estado um produto da sociedade civil, expressando suas contradições e as perpetuando (MONTAÑO; DURIGUETTO, 2011). Para Marx e Engels, longe de ser o momento de universalização, o Estado emerge das relações de produção e expressa os interesses da estrutura de classe inerente às relações sociais de produção. Em outros termos, a forma do Estado emerge das relações de produção (CARNOY, 2015.).

Assim, a burguesia, ao ter o controle dos meios de produção e ao ter o controle sobre o trabalho no processo de produção, passa a constituir a classe dominante, estendendo seu poder ao Estado, que passa a expressar os seus interesses, em normas e leis (MONTAÑO; DURIGUETTO, 2011). Marx denuncia, assim, a falsa autonomia que Hegel confere ao Estado como esfera que realiza a mediação universal dos interesses privados e gerais, pois expressa uma transposição especulativa da vida concreta e real do bourgeois (indivíduo privado e seus interesses particulares) em citoyen (a figura do cidadão e de seus abstratos interesses públicos universais) (ibidem, p. 36).

É nesse sentido que ele entende o Estado sendo representado pelo ponto de vista e dirigido por quem detém o poder, ou seja, como um instrumento da classe dominante, conservando e reproduzindo os interesses desta. Fica reafirmada a dependência direta do Estado ao poder econômico, social e político da burguesia. Nesse sentido, o Estado é a expressão das relações sociais de produção existentes na sociedade capitalista (ibidem, p. 39). 
Marx e Engels (2017) explicitam essa concepção no Manifesto do Partido Comunista, ao afirmarem que a burguesia conquistou a soberania política exclusiva no Estado representativo moderno. Na visão marxiana, o governo moderno não é senão um comitê para gerir os negócios comuns de toda a classe burguesa, e suas formas institucionais se valeriam, essencialmente, da coerção ou da opressão para exercer suas funções e o domínio de classe burguês. Assim, o Estado é a instância que diz representar o interesse universal, mas representa o de uma classe.

Tal Estado cumpre a universalidade, reproduzindo o interesse da classe dominante, adquirindo, assim, a aparência da universalidade, mas a sua realidade efetiva é particular, na medida em que ele garante a organização das condições gerais de um sistema social (ou organização da produção) no qual e pelo qual a burguesia existe como classe dominante. Nesse sentido, o Estado é a expressão política da dominação burguesa, ou seja, porque a burguesia tem um controle especial sobre o trabalho no processo de produção capitalista, como classe dominante ela estende seu poder ao Estado e a outras instituições. Dessa forma, o Estado não está acima dos conflitos de classes (CARNOY, 2015, p. 69).

A definição do Estado enquanto comitê da burguesia gerou diversas interpretações que entendiam a tese de Marx a partir de um economicismo vulgar. Antônio Gramsci chamou essas análises de economicistas ou mecanicistas, por incorrerem em um determinismo do econômico sobre o político, o social e o ideológico. Segundo Mendonça (2014, p. 32), "gestava-se, assim, uma variante da matrizmarxiana onde o Estado, no lugar do papel de Sujeito ocupado na matriz liberal, erigia-se em Estado Objeto". Essa perspectiva supõe uma relação imediata entre os proprietários e o Estado, perdendo de vista a complexidade social e histórica que formam esta relação.

Segundo Pinto e Balanco (2014, p. 41), no Manifesto do Partido Comunista, podemos localizar uma referência à igualdade entre poder de classe e poder de Estado, quando afirmam que o Estado trata-se de um "comitê para gerir os negócios comuns de toda a classe burguesa". Para eles, isto significa que "o Estado, embora contrarie às vezes os interesses imediatos dos capitalistas individuais, atua em prol, no longo prazo, dos capitalistas como coletivadade".

Segundo Carnoy (2015), desde que não fica claro, em Marx, até que ponto o Estado é um agente da burguesia dominante, os marxistas têm apresentado várias respostas diferentes para explicar porque o Estado deveria ser considerado como um instrumento da classe dominante. Nesse sentido, esse autor aponta três grandes linhas dessas respostas: (1) os membros do sistema de Estado tendem a pertencer à classe dominante; (2) a burguesia domina o Estado por meio de seu poder econômico global; (3) a natureza do Estado é determinado pela natureza e pelas exigências do modo de produção capitalista (ibidem). Há, entre os marxistas, portanto, um debate sobre a possível autonomia relativa do Estado frente à burguesia como classe dominante, isto é, momentos em que o poder de Estado se descola do poder de classe.

É importante advertir que as análises que conformaram uma tradição marxista, sobretudo ao longo do século XX, resultam de interpretações realizadas em contextos políticos, sociais e econômicos muito diversos daquele vivido por Marx, onde o capital já se encontrava em sua fase superior, e que estas derivam de apropriações sobre uma teoria do Estado que nunca foi plenamente sistematizada. O propósito de realizá-la como continuidade dos estudos da "Crítica da Economia Política" (MARX, 1996) nunca chegou a se concretizar, pois antes do término da obra "O Capital" seu autor veio a falecer. Hegel e Marx produziram sua práxis no período marcado pelo deslocamento da burguesia ao poder.

É importante destacar que a produção teórica realizada por Gramsci é tributária da leitura da obra de Marx e Engels, suficientemente difundida nos primeiros anos do século passado na Itália entre a militância socialista. Além dessa referência, havia, sobretudo a partir 
do fim da segunda década, grande influência de Lenin que, na época, liderava o governo soviético em meio à guerra civil contra as forças do exército branco, representante militar dos interesses da família do Czar, da burguesia russa e dos investidores estrangeiros ameaçados pelas primeiras iniciativas da política econômica do governo revolucionário na Rússia.

A influência da vitória bolchevique na Rússia foi sentida em diferentes partes do mundo, inspirando os diversos partidos e organizações revolucionárias existentes nos países. As principais preocupações teóricas de Gramsci refletiam as condições da correlação de forças entre as classes sociais da Itália e no mundo. Isto levou Gramsci a refletir sobre a mudança política do Estado na conjuntura de desenvolvimento desigual e dependente do capitalismo. O resultado dessa reflexão foi sistematizado através do conceito de Estado integral ou, como propôs Cristine Buci-Gluksmann (1980), Estado Ampliado. São nesses aspectos que a obra de Gramsci supera, dialeticamente, as formulações acerca de Estado e sociedade civil em Hegel e Marx.

O Estado, segundo Gramscinão é sujeito - uma espécie de entidade que paira sobre a sociedade e os conflitos sociais - nem objeto, mas uma relação social, ou seja, uma condensação das relações sociais definidas pela luta entre as classes sociais (GRAMSCI, 1991). O Estado é compreendido em sua forma integral, sendo esta, certamente, a maior contribuição teórico-metodológica gramsciana à tradição filosófica marxista. Portanto, aquilo que na história da disciplina ciência política foi sempre compreendido enquanto um conceito apreendido de formas diversas, desde a tradição jusnaturalista até o próprio marxismo, desde o próprio Marx até Lenin, nas formulações produzidas pelo italiano vai além, sendo uma fundamental ferramenta metodológica, fornecendo um roteiro de pesquisa. Segundo Mendonça,

O conceito de Estado ampliado permite verificar a estreita correlação existente entre as formas de organização das vontades (singulares e, sobretudo, coletivas), a ação e a própria consciência (sociedade civil) - sempre enraizadas na vida socioeconômica - e as instituições específicas do Estado em sua acepção restrita (sociedade política). Gramsci supera os dualismos das análises que separavam e contrapunham a base à superestrutura, integrando sociedade política e sociedade civil numa só totalidade, em constante interação, no âmbito do que ele considerava as superestruturas (MENDONÇA, 2014, p.38).

Gramsci (2007) ressalta que é incorreto, simplista e apenas funciona de modo esquemático separarmos e desvincularmos Estado e sociedade civil, pois ambos estão, ao mesmo tempo, juntos e separados. No seu entendimento, Estado é igual à sociedade civil mais sociedade política, isto é, "hegemonia encouraçada de coerção" (GRAMSCI, 1930-1932 apudBUCI-GLUCKSMANN, 1980, p. 97). Nessa compreensão, o Estado, apesar de estar a serviço da classe dominante que o dirige, não se mantém apenas por meio da força e da coerção legal. Ele exerce sua dominação de um modo mais sutil e eficaz, isto é, pela obtenção de consentimento dos dominados. Isso se dá com a utilização de aparelhos de hegemonia. $\mathrm{Na}$ leitura gramsciana, o Estado, portanto, tem um importante papel nos campos cultural e ideológico, bem como na organização do consentimento (MILLIBANDapudBOTTOMORE, 1988, p. 136).

Gramsci formula sua concepção sobre o Estado no sentido de um Estado ampliado ou Estado integral, que não nega a compreensão de Estado desenvolvida por Marx, Engels e Lenin. Conforme Buci-Glucksmann (1980, p. 127-128), no curso de suas obras, Gramsci, progressivamente, distingue dois conceitos de Estado, ou mais precisamente dois momentos de articulação do campo estatal: o Estado em sentido estrito (unilateral), e o Estado em sentido amplo, dito integral. Em um sentido estreito, o Estado se identifica com o governo, com o aparelho de ditadura de classe, na medida em que ele possui funções coercitivas e econômicas. A dominação de classe é exercida através do aparelho de Estado no sentido 
clássico (exército, polícia, administração, burocracia). Mas essa função coercitiva é inseparável de um certo papel adaptativo-educativo do Estado, que procura realizar uma adequação entre aparelho produtivo e moralidade das massas populares. Sobre esse aspecto educativo do Estado (Estado educador), Gramsci, no volume 3 dos Cadernos do cárcere Maquiavel: notas sobre o Estado e a política, afirma como papel do Estado educador:

Criar novos e mais elevados tipos de civilização, de adequar a "civilização" e a moralidade das mais amplas massas populares às necessidades do contínuo desenvolvimento do aparelho econômico de produção e, portanto, de elaborar também fisicamente tipos novos de humanidade(GRAMSCI, 2000, p. 23 apudNEVES, 2005, p. 26).

Entendendo que o Estado desenvolve, paralelamente, e, de forma inseparável, ao "funcionamento da coerção", um funcionamento ao nível da ideologia e da economia, isso, necessariamente, passa pelo campo complexo das superestruturas, o que levou Gramsci a formular sua concepção de Estado ampliado. Assim, ao lado do Estado em sentido estrito, Gramsci coloca o Estado em um sentido amplo. O Estado ampliado ou integral pressupõe a tomada em consideração do conjunto dos meios de direção intelectual e moral de uma classe sobre a sociedade, a maneira como ela poderá realizar sua "hegemonia", ainda que ao preço de "equilíbrios de compromisso", para salvaguardar seu próprio poder político, particularmente ameaçado em períodos de crise (BUCI-GLUCKSMANN, 1980, p. 128-29). Assim, "o Estado é todo o conjunto de atividades teóricas e práticas com as quais a classe dirigente justifica e mantém não somente a sua dominação, mas também consegue obter o consenso ativo dos governados" (GRAMSCI, 1955, apudBUCI-GLUCKSMANN, 1980, p. 129).

Na sociedade capitalista, o poder do Estado para disciplinar e punir, isto é, aquilo que Gramsci chama de dominação, mantém-se firmemente e torna-se mais formidável à medida que as várias tecnologias de opressão começam a proliferar. O papel das instituições da sociedade civil (escolas, famílias, igrejas, meios de comunicação etc.) é complementar no processo de controle social. Portanto, o Estado burguês recorrerá à violência direta se for obrigado, mas, ao fazê-lo, arrisca-se a sofrer uma drástica perda de credibilidade ideológica. É, então, preferível que o poder permaneça convenientemente invisível, disseminado por toda a textura da vida social, naturalizado, assim, como costume, hábito, prática espontânea, pois, assim que o poder mostra seu jogo, pode transformar-se em objeto de contestação política (EAGLETON, 1997).

Nessa nova articulação do conceito de Estado, que incorpora a hegemonia ao Estado, Gramsci rejeita qualquer distinção orgânica entre sociedade civil e Estado, hegemonia e ditadura. Mas, isso não significa que um Estado totalitário necessariamente será integral, já que o Estado integral pede um desenvolvimento rico, articulado, das superestruturas, que exclui a possibilidade da sua redução somente ao governo/força, mesmo ele sendo completado ideologicamente (BUCI-GLUCKSMANN, 1980).

É a partir dessa compreensão do funcionamento do Estado que Gramsci considera que o Estado moderno ao subordinar os grupos sociais à hegemonia ativa do grupo dominante $\mathrm{e}$ dirigente, redefinindo suas práticas, torna-se um Estado educador. Nesse sentido, "ao Estado capitalista impõe-se a complexa tarefa de formar um certo 'homem coletivo', ou seja, conformar técnica e eticamente as massas populares à sociabilidade burguesa" (NEVES, 2005, p. 26). Assim, as contradições, sobretudo as mais agudas e antagônicas, entre a sociedade civil e a sociedade política (os governantes do Estado), são manejadas e diluídas.

O Estado educador, como elemento de cultura ativa, deve servir para determinar a vontade de construir, no invólucro da sociedade política, uma complexa e bemarticulada sociedade civil, em que o indivíduo particular governe por si sem que, por isso, esse autogoverno entre em conflito com a sociedade política, tornando-se, 
ao contrário, sua normal continuação, seu complemento orgânico (GRAMSCI, 2000, apudNEVES, 2005, p. 26).

O Estado Ampliado gramsciano, segundo Mendonça (2014), mais do que um sofisticado conceito, representa uma proposta metodológica, fornecendo um roteiro de pesquisa acerca das transformações do Estado e das políticas públicas. Portanto, mais do que um conceito em meio a um amplo quadro teórico, a formulação gramsciana fornece um itinerário de investigação. O itinerário proposto por Gramsci tem como ponto de partida a sociedade civil e, mais particularmente, as organizações que dão direção política às classes sociais, visando detalhar suas formas de organização, suas bases sociais, atuação e formação dos intelectuais orgânicos, disputas endógenas e exógenas às classes sociais e suas respectivas frações. Sobre esse primeiro passo na investigação, é importante notar que o conceito de sociedade civil é compreendido a partir da organização das classes sociais em disputa pelo poder, enquanto arena de disputas, vinculadas de forma mediada aos interesses estruturais que localizam as classes na produção.

A investigação dos partidos das classes em disputa na sociedade civil exige da pesquisa o levantamento dos documentos - revistas, jornais informativos, atas, projetos, programas, propagandas - que permitam inferir a atuação cotidiana destas organizações. Estas informam sobre a ação dos militantes, tanto dirigentes, quanto, porventura, de frações nãodirigentes no interior do partido. A atuação dos intelectuais, assim como em relação aos partidos, é compreendida enquanto ação coletiva que não se restringe à sociedade civil, mas se estende à inserção dos interesses partidários junto aos organismos estatais (Ministérios, Secretarias, comissões públicas). Ambos, tanto partidos quanto os intelectuais, na teoria gramsciana, cumprem funções históricas similares de síntese e mediação entre as necessidades objetivas da classe que representam e a direção ético-política que orienta a formação hegemônica da mesma.

O partido, diferentemente de outras formas de organização muito tradicional, não é um organismo corporativo - "um comerciante não ingressa num partido político para comerciar, nem um industrial para produzir mais e com custos reduzidos, nem um camponês para aprender novos métodos de cultivar" (GRAMSCI apud COUTINHO, 2011, p. 212) - mas um organismo responsável pela homogeneidade e consciência da classe que representa. A atividade partidária, na análise gramsciana, não se restringe aquelas desenvolvidas nos espaços parlamentares ou nos gabinetes governamentais. A função de um partido transcende a institucionalidade político-eleitoral. Nesse sentido, um jornal, uma revista ou uma associação são também partidos ou frações de partidos.

NicosPoulantzas (1936-1979), filósofo, sociólogo e membro do Partido Comunista da Grécia (KKE), foi outro importante marxista que formulou uma teoria sobre o Estado capitalista, adotando uma perspectiva relacional que compreende o Estado, sobretudo em seus últimos trabalhos, como um campo e um processo estratégicos onde se entrecruzam núcleos e redes de poder (PINTO; BALANCO, 2014). Em um primeiro momento de sua obra, Poulantzas partiu de uma leitura estruturalista de Marx, efetuada por Louis Althusser, para investigar o Estado. Mas, diferentemente de seu então professor, ele concentrou-se mais nas análises das classes sociais e na política do que na teoria marxista como um todo (CARNOY, 2015). A principal contribuição de Poulantzas ao debate sobre o Estado capitalista é sua análise do Estado em relação à luta de classes. O intelectual grego concentrou-se no estudo da natureza das classes sociais, no papel do Estado na formação e na definição do conflito de classes e no efeito deste conflito sobre o próprio Estado. Suas investigações nos permitem compreender um Estado que se insere nas e se define pelas relações de classe (as "estruturas" da sociedade capitalista), ao mesmo tempo em que é um fator de coesão e regulamentação do sistema social no qual funciona (CARNOY, 2015, p. 132). 
É importante sinalizar que as teorias de Poulantzas sobre o Estado capitalista sofreram significativas alterações e revisões ao longo dos anos, entre a publicação de Poder político $e$ classes sociais, em 1968, e $O$ Estado, o poder, o socialismo, em 1978. No decorrer de sua obra, Poulantzas foi recorrendo menos a Althusser e mais às formulações de Gramsci. Em sua trajetória intelectual, o marxista grego radicado na França passou por um período de transição, no qual se movia de uma análise existencial-marxista sartreana acerca da lei e da filosofia do direito para uma análise estrutural marxista da região do político nas formações sociais capitalistas. Período este no qual Poulantzas não apenas escreveu sobre a filosofia do direito e sobre aspectos jurídico-políticos do Estado, como sobre o estruturalismo marxista de Althusser, sobre o conceito gramsciano de hegemonia e sobre o marxismo historicista de teóricos britânicos como Anderson e Nairn. Ao longo dessa transição, Althusser forneceu-lhe os meios filosóficos para quebrar o sobreontologismo do existencialismo de Sartre, e, assim, ultrapassar uma explicação humanista e historicista do Estado capitalista; por sua vez, Gramsci, forneceu-lhe os conceitos substantivos que lhe permitiram situar suas ideias sobre a lei e o Estado em um contexto mais amplo das sociedades capitalistas (JESSOP, 2009).

Em sua primeira fase, na época de Poder político e classes sociais, sob uma leitura estruturalista, para Poulantzas "o Estado reproduz a estrutura de classes porque é uma articulação das relações econômicas de classe, na 'região' política. A forma e a função do Estado, portanto, moldam-se pela estrutura das relações de classe" (CARNOY, 2015, p. 132).

Além disso, o Estado é específico ao modo de produção: Estado capitalista, Estado feudal etc. Poulantzas, aqui, recorre ao conceito de Althusser sobre a autonomia relativa da economia e da política, argumentando que o Estado capitalista é, ao mesmo tempo, um Estado de classe e deve ser relativamente independente da luta de classes na produção para funcionar realmente como um Estado de classe. Entretanto, o Estado relativamente autônomo serve como o local da organização do grupo hegemônico da classe capitalista fracionada. A luta dos trabalhadores apenas molda o Estado na medida em que faz parte das relações de classe na produção (CARNOY, 2015).

A partir de 1973, ele começa a rever suas formulações iniciais e passa a admitir que há uma relação diferente entre as classes sociais e o Estado dependendo do estágio do desenvolvimento capitalista. Desse modo, mudanças nas relações capitalistas de produção moldam as instituições políticas, isto é, a estrutura do Estado capitalista não é uma estrutura, mas aparelhos moldados pela luta de classes e pelas correspondentes transformações na produção capitalista (CARNOY, 2015). Assim, Poulantzas vai abandonando o Estado estruturalista em favor de um Estado moldado pela dinâmica da luta de classes.

O auge dessa mudança se concretiza em O Estado, o poder, o socialismo, de 1978, quando a autonomia relativa do Estado se faz dialética, passando a existir a possibilidade da luta de classes no interior dos aparelhos do Estado devido às próprias contradições inerentes à autonomia. São elas e o papel dos movimentos sociais na conformação do Estado que se tornam importantes nessa última fase de Poulantzas. Nessa formulação, o Estado capitalista torna-se muito mais que o local de organização do poder da classe dominante por parte do grupo dominante, mais que o unificador das frações da classe capitalista e o individualizador isolador da classe operária. O Estado passa a ser um local de conflito de classes, no qual o poder político é contestado, sendo moldado pelas lutas na produção e no seio do Estado, sendo ainda considerado um Estado de classe (CARNOY, 2015).

Um conceito central na teoria de Estado de Poulantzas é o de bloco no poder, o qual dialoga com a problemática da hegemonia conforme desenvolvida por Gramsci. Os intelectuais orgânicos atuam na sociedade civil, podendo se inserir em agências da sociedade política estratégicas às suas respectivas frações da classe dominante. Segundo NicosPoulantzas (1986, 2000), a classe capitalista, ao mesmo tempo em que mantém uma unidade política em relação à classe historicamente antagônica, diferencia-se internamente de 
acordo com os interesses econômico-corporativos. Essa diferenciação tem uma natureza econômica, mas também política, uma vez que as frações possuem interesses específicos e se posicionam no interior do Estado de forma particular. Assim, o bloco no poder é "a unidade contraditória particular das classes ou frações de classe politicamente dominantes, na sua relação com uma forma particular do Estado capitalista" (POULANTZAS, 1986, p. 229). Em outras palavras,

\begin{abstract}
[...] o bloco no poder é uma unidade contraditória entre distintas classes e/ou frações de classes, sob a hegemonia, no seu interior, de uma dessas frações, em suas relações com o Estado capitalista. Essa categoria mediadora pode ser utilizada tanto no plano econômico da concorrência capitalista (luta econômica de classes) como no plano político das práticas políticas de classe (luta política de classes), refletindo o conjunto das instâncias, das mediações e dos níveis da luta de classes (POULANTZAS, 1986 apudPINTO et al, 2016, p. 9).
\end{abstract}

Segundo Saes (2014, p.108), a diferenciação política interna da classe capitalista não é "um processo único e irreversível. A emergência organizacional das frações capitalistas é um processo intermitente, com idas e vindas, que depende não só de fases do capitalismo como da evolução da política de Estado". O fracionamento da classe dominante, historicamente, esteve associado às necessidades do capital em acelerar e baratear o processo econômico estruturado nas funções monetárias, produtivas e mercantis. Assim, a classe dominante se diferenciou em agentes sociais distintos, ou seja, em frações (comercial, industrial, bancária e agrária).

Essa diferenciação gera entre as frações interesses diversos, correspondentes à luta pelo aumento na participação da extração da mais valia geral, gerada no processo de expropriação conduzida pela classe dominante. Nesse sentido, os partidos e intelectuais orgânicos dessa classe são os responsáveis pela inserção dos interesses de suas respectivas frações no interior das agências da sociedade política, tendo em vista o objetivo de obter a direção das políticas públicas. Nessa disputa pelo poder, enquanto algumas frações da classe dominante detém a hegemonia, em uma dada conjuntura, as demais frações da mesma classe passam à posição nãohegemônica, ou seja, não é possível em um contexto político ou em uma determinada política pública a satisfação igualitária e homogênea de toda a classe dominante. Em qualquer ação produzida em uma agência da sociedade política os efeitos produzidos afetam todas as frações, mas de forma heterogênea, favorecendo mais algumas do que outras.

A estruturação da classe dominante, segundo as funções do capital, e seu fracionamento foram identificadas por NicosPoulantzas(1986, 2000), a partir de duas formas de diferenciação no interior da classe dominante: a segmentação dessa classe pode ocorrer em função da escala do capital e de acordo com o modo de inserção no sistema econômico capitalista internacional. As disputas no interior da classe dominante em torno da luta pela direção da sociedade política podem ocorrer dentro de um mesmo capital (agrário, bancário, industrial e comercial), entre empresas que funcionam com diferentes níveis de investimento, números distintos de trabalhadores empregados e graus desiguais de tecnologias. A tendência do capital à concentração de capital não elimina, em alguns setores da economia, a necessidade do pequeno e médio capital. Por fim, o último tipo de fracionamento analisado por Poulantzas $(1986,2000)$ resulta da diferença do modo de inserção do capital no sistema econômico internacional e, nesse sentido, distingue dois tipos de segmentação: aquela composta por capitalistas que exploram o mercado interno, defendendo políticas que dinamizem a renda nacional, e outra, associada e dependente ao capital estrangeiro.

\title{
4 Considerações finais
}

Esta breve caracterização nos ajuda a desfazer algumas leituras equivocadas que costumam ser feitas. A principal delas é a de relacionar o Estado somente ao interesse 
público, ignorando que ele está atravessado por interesses privados. Essa é uma visão ingênua e idealizada de Estado que precisa ser desconstruída. Além disso, há movimentos de disputas/tensionamentos e de unidade entre os interesses das frações da classe dominante e, em certa medida, de incorporação de interesses da classe dominada, dentro dos aparelhos de Estado, como forma de assegurar a hegemonia das frações da classe dominante na sociedade. Por fim, cabe frisar que há pontos em comum e divergências teóricas entre os diversos autores marxistas que se dedicaram a formular sobre o Estado capitalista. $\mathrm{O}$ objetivo desteartigo foi apresentar algumas dessas concepções, com vistas nos possíveis diálogos e críticas entre as apropriações dos mesmos.

Do ponto de vista das pesquisas em educação ambiental, as políticas públicas configuram-se como subsídios, tanto do ponto de vista de prover recursos para financiar projetos, quanto de definir e referendar concepções particulares de educação, de educação ambiental, de Estado, de sociedade civil e da relação público-privado. As diferentes vertentes de educação ambiental nos permitem compreender como esta vem sendo instituída nos espaços nos quais é trabalhada (escolas, licenciamento, unidades de conservação e demais áreas protegidas, junto aos movimentos sociais, ONGs, empresas etc). A proposta, aqui, é fomentar essas discussões no campo das políticas públicas de EA, considerando que são bastante escassas as reflexões nesse sentido e por entender-se ser este um tema estratégico para pensar a formação e as práticas de EA.

Conforme argumentamos no artigo, considerando a diversidade de perspectivas teórico-metodológicas adotadas nas pesquisas sobre políticas públicas em EA, consideramos ser fundamental a explicitação dos pressupostos e conceitos que as orientam. Estado é uma categoria central para o debate e a análise sobre políticas públicas. Portanto, entendemos que é preciso situar epistemologicamente, em termos dos paradigmas, as concepções de Estado que vêm sendo empregadas nas pesquisas sobre políticas públicas no campo da educação ambiental, indicando, assim, de qual Estado os pesquisadores do campo falam, quais são suas possibilidades e limites, bem como os papéis das políticasde educação ambiental no contexto do Estado brasileiro.

\section{Referências}

BALL, S. J.; MAINARDES, J. (Orgs). Políticas educacionais: questões e dilemas. São Paulo: Cortez Editora, 2011.

BATISTA, M. S. S. Políticas públicas de educação ambiental: a gestão do Programa Municipal de Educação Ambiental de Mossoró-RN. 2007. 161f. Dissertação (Mestrado em Educação) PPGE/DEPED, Universidade Rio Grande do Norte, Natal, 2007.

BOTTOMORE, T. Dicionário do pensamento marxista. Rio de Janeiro: Jorge Zahar, 1988.

BRANDÃO.G. M. Hegel: o Estado como realização histórica da liberdade. In: WEFFORT, F. C. (Org.). Os clássicos da política 2. 11 ed. São Paulo: Ática, 2006, p. 101-114.

BUCI-GLUCKSMANN, C. Gramsci e o Estado. Rio de Janeiro: Paz e Terra, 1980.

CARNOY, M. Estado e teoria política. Campinas: Papirus, 17 ed., 2015.

CARVALHO, L. M. Demandas e agendas da pesquisa em educação ambiental no Brasil: sentidos construídos a partir dos relatos dos Grupos de Discussão de Pesquisa em Educação Ambiental (GDPsEPEAS). Pesquisa em Educação Ambiental, Rio Claro, v. 11, n. 2, p. 146-167,jul./dez. 2016. 
CHÁVEZ, J. C. M.; MATHEUS, C. E. Educação ambiental e políticas públicas. Revista Biociência, Taubaté, v.10, n. 1-2, p. 25-30, jan./jun. 2004.

CHADDAD, F. R. Educação ambiental como política pública no contexto do desenvolvimento sustentável proposto pela ONU. Enciclopédia Biosfera, Goiânia, vol.7, n.12, p. 65-74, 2011.

COUTINHO, C. N. De Rosseau a Gramsci: ensaio de teoria política. São Paulo: Boitempo, 2011.

EAGLETON, T. Ideologia - uma introdução. São Paulo: EDUNESP/Boitempo, 1997.

ENGELS, F. A origem da família, da propriedade privada e do Estado. São Paulo: Centauro, 3. ed., 2006.

EVANGELISTA, O. (Org). O que revelam os slogans na política educacional. Araraquara: Junqueira\&Marin, 2014.

FONTES, V. Sociedade civil no Brasil contemporâneo: lutas sociais e luta teórica na década de 1980. In: LIMA, J. C. F.;NEVES, L. M. W. (Orgs.). Fundamentos da Educação escolar do Brasil contemporâneo. Rio de Janeiro: Fiocruz, 2006. p. 201-239.

COUTINHO, C. N. (Org.). O leitor de Gramsci: escritos escolhidos 1916-1935. Rio de Janeiro: Civilização Brasileira, 2011.

GRAMSCI, A. A concepção dialética da história. Rio de Janeiro: Civilização Brasileira, 1991.

GRAMSCI, A. Cadernos do Cárcere. Vol. 3. Maquiavel: notas sobre Estado e a Política. Rio de Janeiro: Civilização Brasileira, 2007.

GRUPPI, L. Tudo começou com Maquiavel - As concepções de Estado em Marx, Engels, Lenin e Gramsci. Porto Alegre: L\&PM, 1980.

JESSOP, B. Althusser, Poulantzas, Buci-Glucksmann: desenvolvimentos ulteriores do conceito gramsciano de Estado Integral. Crítica Marxista, Campinas, n. 29, p. 97-121, dez. 2009.

KAPLAN, L. Análise crítica dos discursos presentes nos documentos que definem a política de educação ambiental no Brasil. 2011. 369 p. Dissertação (Mestrado em Educação), Universidade Federal do Rio de Janeiro, Rio de Janeiro, 2011.

LAYRARGUES, P. P. Políticas públicas para a educação ambiental no processo de gestão ambiental participativa: atores sociais para a construção da sociedade justa e sustentável. In: LOUREIRO, C. F. B. (Org.) Cidadania e meio ambiente. Salvador: CRA. p. 59-71. 2003.

MARX, K. Para a crítica da economia política. São Paulo: Nova Cultural, 1996.

MARX, K. Manifesto do Partido Comunista.In: Reis Filho, D. A. (Org.). O Manifesto do Partido Comunista 150 anos depois. Rio de Janeiro: Contraponto, 1998. p. 07-41.

MARX, K. Manuscritos Econômicos e Filosóficos.São Paulo: Martin Claret, 2003.

MARX, K. Prefácio. Contribuição à Crítica da Economia Política. 2. ed. São Paulo: Expressão Popular, 2008.

MARX, K. A revolução antes da revolução, vol. 2. As lutas de classes na França. São Paulo: Expressão Popular, 2008a. 
MARX, K. A revolução antes da revolução, vol. 2. A guerra civil na França. São Paulo: Expressão Popular, 2008b.

MARX, K. O 18 Brumário de Luis Bonaparte.São Paulo: Boitempo, 2011.

MARX, K. Crítica do Programa de Gotha. São Paulo: Boitempo, 2012.

MARX, K. Crítica da filosofia do direito de Hegel. São Paulo: Boitempo, 3 ed., 2013.

MARX, K.; ENGELS, F. A ideologia alemã. São Paulo: Boitempo, 2017.

MARX, K.; ENGELS, F. Manifesto Comunista. São Paulo: Boitempo, 2017a.

MENDONÇA, S. R. Estado e Sociedade.In: MATTOS, M. B. (Org.). História: pensar e fazer.Rio de Janeiro: Laboratório Dimensões da História, 1998, p. 13-32.

MENDONÇA, S. R. O Estado Ampliado como ferramenta metodológica. Revista Marx e o marxismo, Niteroi, v. 2, n. 2, 27-43, Jan./Jul. 2014.

MONTAÑO, C.; DURIGUETTO, M. L. Estado, Classe e Movimento Social. São Paulo: Cortez Editora, 2 ed., 2011.

NERY-SILVA, A. C.; SANTANA, L. C. Pesquisa em educação ambiental e políticas públicas: processos de formulação e implementação abordados nas dissertações e teses brasileiras da área. In:Encontro Pesquisaem Educação Ambiental - EPEA, 2015, Rio de Janeiro. Anais do VIII EPEA, 2015, p.01-13. Disponível em http://epea.tmp.br/epea2015_anais/pdfs/plenary/26.pdf.

NETTO, J. P. (Org.) O leitor de Marx. Rio de Janeiro: Civilização Brasileira, 2012.

NEVES, L. M. W. (Org.)A nova pedagogia da hegemonia: estratégias do capital para educar o consenso. São Paulo: Xamã, 2005.

PINTO, E. C.; PINTO, J. P. G.; BARUCO, G.; SALUDIJAN, A.; BALANCO, P.; SHONERWALD, C.; NOGUEIRA, I. A economia política dos governos Dilma: acumulação, bloco no poder e crise. Textos para discussão. Fevereiro de 2016. Disponível em: http://www.ie.ufrj.br/index.php/indexpublicacoes/textos-para-discussao. Acesso em: 16 dez. 2016.

PINTO, E. C.; BALANCO, P. Estado, bloco no poder e acumulação capitalista: uma abordagem teórica. Revista de Economia Política, São Paulo, v. 34, n. 1, p. 39-60, jan./mar.2014.

POULANTZAS, N. Poder político e classes sociais. 2 ed. São Paulo: Martins Fontes, 1986.

POULANTZAS, N. O Estado, o poder, o socialismo. 4 ed. São Paulo: Paz e Terra, 2000.

SAES, D. As frações da classe dominante no capitalismo: uma reflexão teórica. In PINHEIRO, M. (Org.) Ditadura. O que resta da transição?São Paulo: Boitempo, 2014, p. 105-118.

RODRIGUES, J. N.; GUIMARÃES, M. Políticas públicas e educação ambiental na contemporaneidade: uma análise crítica sobre a Política Nacional de Educação Ambiental (PNEA). Ambiente e Educação, v. 15, n. 2, p. 13-30, 2010.

SANTANA, L. C. Pesquisa em Educação Ambiental e Políticas Públicas: apontamentos e memória de um processo. Pesquisa em Educação Ambiental, Rio Claro, v. 9, n. 1, p. 156-168, jan./jun.2014. 
SANTANA, L. C.; LAMOSA, R. A. C. Pesquisa em Educação Ambiental e Políticas Públicas: desafios políticos e epistemológicos. Pesquisa em Educação Ambiental, Rio Claro, v. 11, n. 2, p. 105116, jul./dez.2016.

SHIROMA, E. O.; MORAES, M. C. M.; EVANGELISTA, O. Política educacional. 4 ed. Rio de Janeiro: Lamparina, 2007.

SORRENTINO, M.; TRAJBER, R.; MENDONÇA, P.; FERRARO JUNIOR, L. A. Educação ambiental como política pública. Educação e Pesquisa, São Paulo, v. 31, n. 2, p. 285-299, mai./ago. 2005.

SOTERO, J. P.; SORRENTINO, M.A educação ambiental como política pública: reflexões sobre seu financiamento. In: V encontro Nacional da Associação Nacional de Pós- Graduação e Pesquisa em Ambiente e Sociedade - ANPPAS, 2010, Florianópolis. Anais... Florianópolis: UFSC, 2010. 